\title{
Assessment of the Extended Theory of Planned Behavior for Nicotine Dependence Prediction: An Application of Path Analysis
}

\author{
Rahim Tahmasebi, ${ }^{1}$ Maliheh Saeed Firoozabadi, ${ }^{1}$ and Azita Noroozi ${ }^{1,}$ \\ ${ }^{1}$ Bushehr University of Medical Sciences, Bushehr, IR Iran \\ "Corresponding author: Azita Noroozi, Bushehr University of Medical Sciences, Bushehr, IR Iran. E-mail: azitanoroozi@yahoo.com
}

Received 2016 December 24; Revised 2016 February 11; Accepted 2017 March 26.

\begin{abstract}
Background: Given the importance of water-pipe smoking cessation in health improvement, further studies are required to identify the predictors of this behavior.

Objectives: This study aimed to examine both one-way direct and indirect effects of the constructs of the extended theory of planned behavior (TPB) on nicotine dependence among women residing in Bushehr, situated in Southwest of Iran.

Methods: This cross sectional study was performed in Bushehr province in Southwest of Iran. In this study, 430 women were selected through multistage, stratified, cluster, random sampling and were evaluated using a self-administered questionnaire. Path analysis was applied to estimate the direct and indirect effects of attitude, perceived norms, and personal agency on nicotine dependence. Results: The results demonstrated that extended TPB is a predictor of nicotine dependence(R2,34\%) and intention to quit water-pipe smoking (R2, 40\%). According to the results, the modified model was a good fit for the data (RMSEA, 0.05; NFI, 0.97; AGFI, 0.91). Selfefficacy (factor loading, -0.30) and perceived behavioral control (factor loading, -0.17) both directly and indirectly affected nicotine dependence through intention. However, in this study, subjective norms did not predict nicotine dependence.

Conclusions: The finding showed that skill-based training should be implemented in interventional programs to increase selfefficacy, alongside policies to constrain access to water-pipe smoking. Therefore, social and cognitive interventions can be effective only in the presence of political changes.
\end{abstract}

Keywords: Nicotine Dependence, Psychological Theory, Behavioral Change, Statistical Model

\section{Background}

There are over 1 billion smokers in the world, with an increasing number being reported in developing countries (1). The world health organization (WHO) predicts that over 8 million deaths will be attributed to smoking by 2030 worldwide (2). The global prevalence of cigarette smoking is $47 \%$ and $12 \%$ in men and women, respectively (3).

A study in the USA revealed that the rate of smoking is reducing among men and increasing among women. In fact, the prevalence of smoking among women has increased by $12 \%$ worldwide (4). Women prefer water pipes to cigarettes, especially in developing countries such as Iran (5). According to a previous study in Iran, 17\% of women and $6.2 \%$ of men preferred water-pipe smoking (6).

Most water-pipe smokers consider it a safe alternative to cigarettes $(5,7,8)$. Nevertheless, water pipe contains most of the toxic elements found in cigarettes, such as monoxide, nicotine, tar, and heavy metals $(9,10)$. A systematic review showed that water pipe is significantly associated with lung cancer, respiratory diseases, low birth weight, and periodontal diseases (11) and may be even as harmful as cigarette smoking (12).
Given the differences in water-pipe use patterns among men and women, further studies are required to identify the predictors of water-pipe smoking cessation in women. In order to increase the likelihood of successful intervention, it is necessary to employ social psychological theories. Such theories can enable us to better understand the processes involved in smoking behaviors. One of the most widely employed theoretical frameworks for explaining health risk behaviors, such as smoking, is the theory of planned behavior (TPB) $(13,14)$.

According to TPB, behavior is a function of intention. On the other hand, intention is determined by attitude (eg, evaluation of the safety of water-pipe use), perceived norms (eg, social training on the use of water pipes), and personal agency (eg, perceived ability to quit water-pipe smoking). Attitude comprises experiential attitude (affective evaluation of smoking) and instrumental attitude (overall evaluation of smoking), which is based on behavioral beliefs (eg, expected consequences of water-pipe use), weighted by the subjective value of the consequences.

Perceived norms include descriptive norms (beliefs about whether most people smoke water pipes) and subjective norms (beliefs about whether most people approve 
or disapprove of water-pipe smoking), which are based on normative beliefs (eg, expectations surrounding people's approval of water-pipe use), weighted by the motivation to comply with these norms. Personal agency includes self-efficacy (the overall measure of the ability to quit water-pipe smoking by overcoming the obstacles) and perceived behavioral control (PBC) (the overall measure of perceived control over water-pipe smoking cessation), which is based on control beliefs (expected resources and obstacles of water-pipe smoking cessation), weighted by the perceived impact of control factors (15).

Several studies have presented strong empirical evidence for predicting the intention of smoking behaviors $(13,16)$. Moreover, in various studies, predictive factors of smoking have been identified, including personal factors (eg, beliefs and attitudes towards smoking) (17-19), social learning factors (eg, family and peer smoking and approval of smoking by friends, family, and other key people in one's life) (19), and self-efficacy $(16,20)$.

WHO has emphasized on the promotion of tobacco control, as the greatest preventable cause of morbidity and mortality (21). Although several studies have shown that the level of tobacco dependence is associated with success in smoking cessation $(16,22-25)$, in our literature search, no study had considered all the constructs of extended TPB. Therefore, the main objective of the present study was to examine the components of extended TPB and to determine how they can predict tobacco dependence in waterpipe smoking women.

\section{Methods}

\subsection{Subjects}

In this cross sectional study, the target group consisted of all female water-pipe smokers, residing in Bushehr, situated in Southwest of Iran; the subjects smoked water pipe at least over the past year. Multistage, stratified, cluster, random sampling was utilized for selecting the participants. Based on the classifications by the municipality, Bushehr was stratified into 75 strata, 20 of which were randomly selected for this study.

Several blocks (as clusters) were randomly selected from each selected stratum. All eligible water-pipe smoking women, residing in these blocks, were invited to participate in the study until the required sample was achieved for the stratum. The sample size for each stratum was determined in proportion to the number of households in the stratum. The sampling frame was designed by the Persian Gulf tropical medicine research center of Bushehr University of Medical Sciences.

The sample size was determined based on the ratio of participants to the number of model parameters. In this regard, Kline showed that 20:1 is a desirable ratio of participants to parameters, while a ratio of 10:1 is more realistic (26). Overall, the hypothesized model in this study incorporated 29 parameters: 15 path coefficients, 5 equation error variances, and 9 independent variable variances. Considering a 15:1 ratio, the sample size was determined to be 435 for the study. In order to allow for potential missing data and to obtain a well-fitting model (almost 5\% attrition rate), the initial sample size was set at 450 .

In the process of sampling, 489 participants were evaluated, 39 of whom did not meet the inclusion criteria. In a total of 450 participants, 15 submitted imperfect data in the questionnaire; therefore, they were excluded from the study. The final sample size in the path analysis was 430 , yielding a $95.5 \%$ response rate. Finally, 430 female waterpipe smokers were recruited from November to March 2015.

The study objectives were verbally explained to the participants. They were assured that the gathered information would remain confidential and anonymous. Those who were interested in participation in the study completed the informed consent forms and the questionnaires immediately on the site. The present study was approved by the university ethics committee (ethics No., IR.BPUMS.REC.1395.161).

\subsection{Data Collection Tools}

The questionnaire in this study comprised of 3 sections: 1) demographic and smoking characteristics; 2) TPB constructs including experiential attitude, instrumental attitude, descriptive norms, subjective norms, self-efficacy, and PBC; and 3) TPB outcomes including intention behind smoking cessation and nicotine dependence.

\subsection{Demographic and Smoking Characteristics}

The demographic characteristics included age, marital status, occupational status, and educational level. Smoking characteristics included the number of water pipes smoked per day or per week.

\subsection{TPB Constructs}

This section of the questionnaire was developed for each TPB construct by using the established TPB scaling methods (15). This section of the questionnaire was prepared with open-ended elicitation interviews to identify relevant behavioral outcomes, referents, and environmental facilitators/barriers of water-pipe smoking. Elicitation interviews were conducted with a sample of 20 water-pipe smoking women. Ten women intended to quit water-pipe smoking, while 10 had no intention to quit water-pipe 
smoking. Afterwards, interviews were content-analyzed, and the content of the questionnaire was prepared.

The prepared questionnaire was reviewed by 10 health education experts. The content validity ratio (CVR) was measured to assess the extent of experts' agreement on the questions. In this study, a CVR of 0.62 or higher (for 10 panelists) indicated good content validity (27). CVR for each question was $\geq 0.64$, and the total CVR of 49 items was calculated to be 0.80 , which was acceptable.

Before data collection, the questionnaires were tested for reliability in a sample of 33 women. Cronbach's alpha coefficient was measured to assess the internal consistency. The Cronbach's alpha coefficients were 0.42, 0.79, $0.86,0.78,0.74$, and 0.87 for experiential attitude, instrumental attitude, descriptive norms, subjective norms, PBC, and self-efficacy, respectively. After item analysis, 1 question was deleted for experiential attitude, and Cronbach's alpha coefficient was estimated at 0.72 .

In this study, the constructs were evaluated by indirect measures (15). The content of this section of the questionnaire is described here. For the assessment of experiential attitude, the participants rated 5 items with a bipolar disagree-agree scale (scored from -2 to +2 ), while experiential attitude was evaluated by summing these 5 items. Instrumental attitude was evaluated by 6 behavioral belief/outcome evaluation pairs, using a bipolar 5-point Likert scale (scored from -2 to +2 ).

For each behavioral belief, the participants indicated how much they agreed or disagreed with the outcome. For each corresponding outcome evaluation, the participants commented on whether the outcome was important or not. Instrumental attitude was analyzed by first multiplying the behavioral beliefs by the corresponding outcome evaluation ratings and then summing the 6 pairs. The positive mean score for experiential and instrumental attitudes demonstrated a positive attitude towards waterpipe use.

Descriptive norms were evaluated by summing 5 items, rated with a bipolar disagree-agree scale (scored from -2 to +2 ); the positive mean score showed that most people smoked water pipes. Subjective norms included 5 normative belief/motivation to comply pairs. The participants rated normative beliefs with a bipolar disagree-agree scale (scored from -2 to +2 ), and motivation to comply was evaluated using a unipolar important-not important scale (scored from 1 to 5 ). The positive mean score showed that most participants approved of water-pipe smoking.

Self-efficacy was evaluated by summing 6 items, rated on a unipolar disagree-agree scale (scored from 1 to 5 ). The positive mean score showed the ability to quit water-pipe smoking. Also, PBC contained 4 control belief/perceived power pairs. The participants rated control beliefs with a bipolar agree-disagree scale (scored from - 2 to +2 ), and perceived power was evaluated using a bipolar difficult-easy scale (scored from -2 to +2 ). Subjective norms and PBC were estimated similar to instrumental attitude. The positive mean score of PBC revealed control over quitting waterpipe smoking.

\subsection{TPB Outcomes}

TPB outcomes included the intention behind smoking cessation and nicotine dependence. Intention to quit water-pipe smoking was measured with 3 items, rated on a unipolar 5-point Likert scale (1, disagree; 5, agree). Intention was evaluated by summing these 3 items, with higher mean scores indicating the intention to quit smoking. Nicotine dependence level was assessed via Shiffman Test for nicotine dependence, including 19 items rated on a unipolar 5-point Likert scale (1, never true; 5, always true) (28).

\subsection{Data Analysis}

Data analysis was performed, using LISREL 8.80 and SPSS version 18 . The applicability of TPB in predicting intention to quit water-pipe smoking was examined by path analysis. Path analysis is employed as a method for studying the direct and indirect effects of variables and estimating the coefficients in the underpinning linear model. The Mardia's coefficients for multivariate skewness and kurtosis were 51.18 and 22.32, respectively. These values were significant $(\mathrm{P}<0.001)$; therefore, some of the variables were not normal. Accordingly, we applied the robust maximum likelihood estimation procedure.

A correlation matrix and an asymptotic covariance matrix were applied for model estimation. Chi square test, adjusted goodness-of-fit index (AGFI $>0.9$ ), and root mean square error of approximation (RMSEA < 0.05) were employed as the model fit criteria. With regard to the comparative fit index, normed fit index (NFI > 0.9) was selected. T value was measured for eliminating the parameters in the path analysis, and a modification index was employed for the inclusion of additional parameters (29).

\section{Results}

A total of 430 participants within the age range of 15-83 years (mean, $36.73 \pm 13.57$ years) were included in the study. Among 303 women who reported their level of education, 19.2\% $(n=58)$ were illiterate, $47.5 \%(n=144)$ had graduated high school, and 33.3\% $(n=101)$ had a college degree. In this study, most of the participants ( $n=258,69.8 \%)$ were housekeepers. 
The majority of women smoked water pipes for 1 - 5 years $(n=225,52.4 \%), 31.6 \%(n=136)$ smoked water pipe for over 10 years, $13.7 \%(n=59)$ smoked for $5-10$ years, and $2.3 \%$ $(\mathrm{n}=10)$ did not report the duration of smoking. Most of the participants in this study had a family history of waterpipe smoking ( $\mathrm{n}=267,62.1 \%$ ).

The average of participants' responses regarding the model constructs, intention, and nicotine dependence is summarized in Table 1 . Based on the analysis of the mean values, the participants believed that they had low levels of self-efficacy and PBC to quit water-pipe smoking. Moreover, the participants had positive attitudes towards water-pipe use. The mean scores of perceived norms revealed that the majority of subjects did not smoke water pipe and did not approve of water-pipe smoking. The results demonstrated that the participants had no intention to quit smoking and had medium levels of nicotine dependence.

The Pearson's correlation coefficients for the constructs, intention, and nicotine dependence are presented in Table 2. Nicotine dependence had a positive association with attitudes and norms. On the other hand, nicotine dependence had a negative association with intention and personal agency. Therefore, patients with high perceived ability, control over water-pipe smoking cessation, and intention to quit smoking showed less nicotine dependence.

A significant positive association was found between intention to quit smoking and personal agency. On the other hand, intention to quit smoking had a negative association with attitudes and subjective norms.

\subsection{Structural Model}

The original hypothesized model did not produce a good fit for the data $\left(\chi^{2}, 147.81 ; \mathrm{df}=40 ; \mathrm{P}<0.001\right.$; RMSEA, 0.08 [0.07 - 0.09]; NFI, 0.96; AGFI, 0.86). Examination of path coefficients in the hypothesized model showed that the path coefficient of subjective norms was insignificant relative to intention. By considering the results of the original model and the related theoretical factors, the model was modified by dropping the paths with insignificant coefficients and adding 2 error covariances.

The fit indices showed improvement in the modified model over the original model $\left(\chi^{2}, 93.36\right.$; df, 38; $\mathrm{P}<0.001$; RMSEA, 0.05 [0.04 - 0.07]; NFI, 0.97; AGFI, 0.91). The critical $\mathrm{N}$ (Hoelter index) in this model was 284.41, which suggests that the sample size cutoff point for testing the model was above satisfactory. The coefficients between the variables improved, and all the paths in the modified model were significant. All fit indices indicated a good fit for the model.

The results indicated that among attitudes, experiential attitude had the greatest effect on intention (factor loading, -0.45) and nicotine dependence (factor loading, 0.06). Among perceived norms, subjective norms could not predict intention or nicotine dependence. In terms of personal agency, self-efficacy had the greatest effect on intention (factor loading, 0.14) and nicotine dependence (factor loading, -0.30).

Self-efficacy and PBC affected nicotine dependence both directly and indirectly through intention with the highest factor loadings of -0.30 and -0.17, respectively. Direct and indirect effects of the constructs on nicotine dependence are presented in Table 3 and Figure 1 . The model accounted for $40 \%$ of variance in intention to quit waterpipe smoking and $34 \%$ of variance in nicotine dependence among female water-pipe smokers.

\section{Discussion}

The present study had 2 major objectives. The first goal was to determine the relationship between TPB constructs and nicotine-dependence behaviors, while the second goal was to determine the power of expanded TPB constructs in the prediction of intention to quit water-pipe smoking and nicotine dependence.

Regarding the first objective, the results showed that the strongest predictor of nicotine dependence is selfefficacy (a subscale of personal agency). This construct had both direct and indirect effects through intention on nicotine dependence, and subjects with higher self-efficacy in water-pipe smoking cessation reported less nicotine dependence; this finding has been confirmed in several studies.

In this regard, in a previous study, low self-efficacy was reported as the strongest predictor of cigarette smoking intention among Chinese teenagers over 6 months and 5 years, respectively (19). In addition, interventions with the aim of self-efficacy improvement have been effective $(30,31)$. A meta-analysis demonstrated the relationship between self-efficacy and smoking cessation (32). Overall, individuals who are more capable of dealing with environmental facilitators and barriers of water-pipe smoking may control smoking better than others, and therefore, show less dependence on nicotine.

Furthermore, PBC, which is another aspect of personal agency, was a predictor of nicotine dependence. This finding is in line with the results of meta-analyses, which showed that health risk behaviors, such as smoking and alcohol use, can be explained by the individual's tendency to exhibit certain behaviors in high-risk environments (facilitators) rather than his/her attitude $(33,34)$.

In terms of health risk behaviors in the environment and social context, community may promote behaviors, which indicate the intention behind smoking cessation, thus increasing the person's dependence. Among PBC subscales, perceived control could best explain behaviors, 
Table 1. The Mean, SD, and Range of Model Constructs and Nicotine Dependence $(n=430)$

\begin{tabular}{lccccccc}
\hline Variables & $\begin{array}{c}\text { Nicotine } \\
\text { Dependence }\end{array}$ & Intention & $\begin{array}{c}\text { Experiential } \\
\text { Attitude }\end{array}$ & $\begin{array}{c}\text { Instrument } \\
\text { Attitude }\end{array}$ & $\begin{array}{c}\text { Descriptive } \\
\text { Norms }\end{array}$ & $\begin{array}{c}\text { Subjective } \\
\text { Norms }\end{array}$ & $\begin{array}{c}\text { Self-Efficacy } \\
\text { PBC }\end{array}$ \\
\hline Mean \pm SD & $40.71 \pm 12.63$ & $8.91 \pm 3.29$ & $0.11 \pm 4.60$ & $0.23 \pm 6.92$ & $-1.11 \pm 4.39$ & $-0.30 \pm 5.38$ & $-0.40 \pm 5.97$ \\
Range scale & 11,88 & 3,15 & $-12,+12$ & $-24,+24$ & $-10,+10$ & $-20,+20$ & $-12,+12$ \\
\hline
\end{tabular}

Abbreviation: PBC, perceived behavioral control; SD, standard deviation.

Table 2. The Correlation Coefficients for the Constructs and Nicotine Dependence $(n=430)$

\begin{tabular}{|c|c|c|c|c|c|c|c|c|}
\hline & $\begin{array}{c}\text { Nicotine } \\
\text { Dependence }\end{array}$ & Intention & $\begin{array}{c}\text { Experiential } \\
\text { Attitude }\end{array}$ & $\begin{array}{c}\text { Instrumental } \\
\text { Attitude }\end{array}$ & $\begin{array}{l}\text { Subjective } \\
\text { Norms }\end{array}$ & $\begin{array}{c}\text { Descriptive } \\
\text { Norms }\end{array}$ & Self-Efficacy & PBC \\
\hline $\begin{array}{l}\text { Nicotine } \\
\text { dependence }\end{array}$ & 1 & & & & & & & \\
\hline Intention & $-0.336^{* *}$ & 1 & & & & & & \\
\hline $\begin{array}{l}\text { Experiential } \\
\text { attitude }\end{array}$ & $0.321^{* *}$ & $-0.572^{* *}$ & 1 & & & & & \\
\hline $\begin{array}{l}\text { Instrumental } \\
\text { attitude }\end{array}$ & $0.154^{* *}$ & $-0.440^{* *}$ & $0.598^{* *}$ & 1 & & & & \\
\hline $\begin{array}{l}\text { Subjective } \\
\text { norms }\end{array}$ & $0.180^{* *}$ & $-0.242^{* *}$ & $0.356^{* * *}$ & $0.322^{* *}$ & 1 & & & \\
\hline $\begin{array}{l}\text { Descriptive } \\
\text { norms }\end{array}$ & $0.204^{* *}$ & 0.019 & $0.199^{* *}$ & $0.11^{*}$ & $0.306^{* *}$ & 1 & & \\
\hline Self-efficacy & $-0.466^{* *}$ & $0.266^{* *}$ & $-0.278^{* *}$ & $-0.127^{* *}$ & $-0.375^{* *}$ & $-0.309^{* *}$ & 1 & \\
\hline PBC & $-0.257^{* *}$ & $0.178^{* *}$ & -0.052 & 0.051 & -0.014 & $0.156^{* *}$ & $0.218^{* *}$ & 1 \\
\hline
\end{tabular}

Abbreviation: PBC, perceived behavioral control.

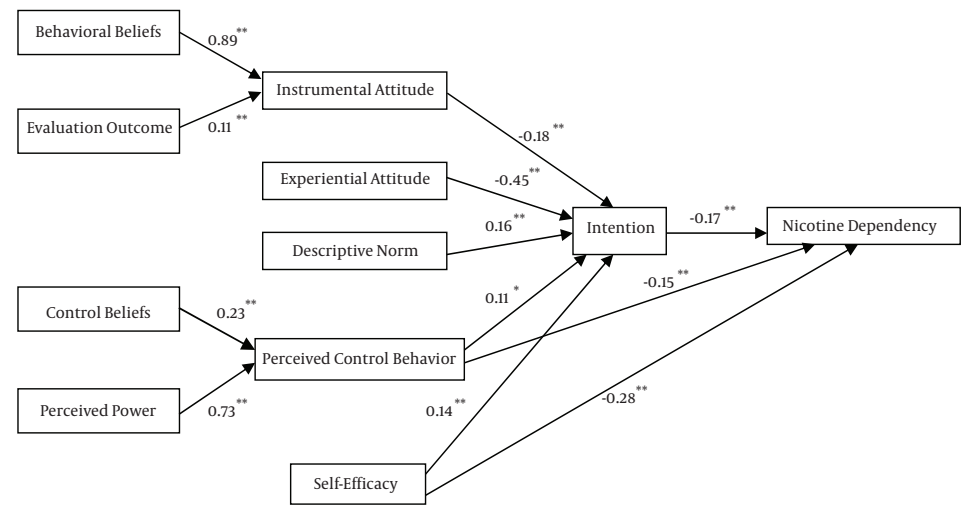

Figure 1. The Diagram of Path Analysis for the Prediction of Nicotine Dependence $\left({ }^{*} \mathrm{P}<0.01,{ }^{* *} \mathrm{P}<0.001\right)$

which reflect the impact of one's perception about difficulties in dealing with environmental facilitators of access to water pipes. Therefore, the need to reduce these facilitators and increase environmental restrictions is strongly felt.

The findings of the present study revealed that intention, which is equal to PBC, is effective in nicotine dependence, while intention only directly affects nicotine depen- dence. In fact, individuals who were willing to quit waterpipe smoking in near future reported less nicotine dependence. Numerous studies have also found that intention to quit cigarette smoking is associated with nicotine dependence, and people who try to quit tobacco smoking have less nicotine dependence $(16,22,24,25)$. These findings were in accordance with the TPB framework, which considers intention as the main requirement of behavior $(13,15)$. 
Table 3. Direct and Indirect Effects of the Constructs on Nicotine Dependence

\begin{tabular}{lccc}
\hline Predictive Constructs & \multicolumn{3}{c}{ Causal Effects } \\
\cline { 2 - 4 } & Direct & Indirect $^{\mathbf{a}}$ & Total \\
\hline Experiential attitude & - & 0.063 & 0.063 \\
\hline Instrumental attitude & - & 0.031 & 0.031 \\
\hline Behavioral beliefs & - & 0.027 & 0.027 \\
\hline Evaluation outcomes & - & 0.003 & 0.003 \\
\hline Descriptive norms & - & -0.027 & -0.027 \\
\hline Self-efficacy & -0.28 & -0.024 & -0.304 \\
\hline PBC & -0.15 & -0.019 & -0.169 \\
\hline Control beliefs & - & -0.039 & -0.039 \\
\hline Perceived power & - & -0.123 & -0.123 \\
\hline Intention & -0.17 & - & -0.17 \\
\hline
\end{tabular}

${ }^{\mathrm{a}}$ Indirect effect through intention.

In the present study, the participants had a relatively neutral attitude towards cessation of water-pipe smoking. In other words, they were not concerned about water-pipe smoking and did not consider the associated complications or negative outcomes after using water pipes. In various studies, the view that water pipe is less harmful than cigarettes is prevalent. Even in several studies, some people believed that the addictive effects of water pipe are not as severe as cigarettes and that water pipe does not contain tar, nicotine, or carbon monoxide $(35,36)$. Therefore, this wrong view has encouraged a neutral attitude towards the cessation of water-pipe smoking.

In line with several previous studies, attitude could explain nicotine dependence in the present study $(31,37)$. In this regard, the results of a recent study revealed that experiential attitude plays a greater role in nicotine dependence than cognitive/instrumental attitude $(19,33)$. The first reason is that the subjects did not consider the significant health consequences of water-pipe use (neutral cognitive/instrumental attitude). Second, the youth comprise the majority of water-pipe consumers. Therefore, explanatory evaluation of health outcomes is minimal, as individuals link the effects and physical consequences of water-pipe smoking to the future and do not feel obliged to take any measures at present. Overall, experiential attitude plays a greater role in nicotine dependence than cognitive attitude.

In the present study, both descriptive and subjective norms were examined. Descriptive norms were the weakest predictors of nicotine dependence. Subjective norms could not predict nicotine dependence and were excluded from the model. According to TPB, proximity to tobacco smokers may affect people's perceptions about tobacco smoking and encourage positive beliefs about tobacco, which can promote smoking intentions and nicotine dependence $(19,38,39)$. Therefore, water-pipe smoking is a more important factor than acceptance/rejection of waterpipe smoking or nicotine dependence.

Previous studies have also confirmed that subjective norms are not predictors of nicotine dependence (19, 33, 37). The researchers assumed that the effect of subjective norms is more significant in collectivistic cultures; however, this finding was not confirmed in the present study. As indicated by Gue et al., subjective norms may have trivial effects on tobacco use in Asian populations, since there is a small chance that many people would recommend tobacco use (40).

Regarding the second objective of the present study, path analysis revealed that TPB constructs, with the exception of subjective norms, were significant predictors of intention to quit smoking and nicotine dependence. The explained variance in intention to quit smoking by the expanded model (40\%) was greater than the variance reported in studies by Lynam et al. and Hu et al. (37, 41) and was almost similar to the value mentioned in a study by Armitage and Conner (42). The variance in nicotine dependence was $34 \%$ in the present study, which has not been reported in similar research. In addition, the present study revealed that extended TPB had a greater explanatory power and could be applied for water-pipe consumers in Iranian female populations.

The present study had several limitations. First, given the cross sectional design of the study, causal relationships could not be established by the findings. Second, bias and self-report might have led to underreporting of nicotine dependence (19). Nevertheless, it is likely that the effects were minimal, as the survey was performed anonymously. Also, comparison with biochemically verified measurements of smoking shows that anonymous self-report surveys are reliable and valid (43). This study was conducted among women who used water pipes; therefore, its applicability among men was not specified, and further studies are recommended in this area. On the other hand, use of extended TPB, as the theoretical framework, and the random sampling procedure were the strengths of this study.

\subsection{Conclusions}

The results of the present study illustrated that interventions for reducing tobacco use not only should focus on changing people's beliefs regarding the hazards of water-pipe smoking, but also should promote skills to improve their ability in facing facilitators of water-pipe use. 
Empowerment and skill-based training should be considered for increasing self-efficacy, along with policies, which can increase environmental constraints of access to water pipes in interventional programs. It is essential that educational programs focus on experiential attitudes rather than physical consequences alone (which affects cognitive attitudes). Women who are in contact with smokers are likely to experience increased nicotine dependence, and as a result, they should be involved in training programs. Finally, it can be stated that social and cognitive interventions are effective in reducing water-pipe use and nicotine dependence only if political changes (eg, banning waterpipe smoking in public places, banning tobacco advertisements, and increasing tobacco prices via taxation) take place.

\section{Acknowledgments}

This paper was extracted from an MSc thesis in health education, submitted to Bushehr University of Medical Sciences, Bushehr, Iran. We gratefully acknowledge the university and all those who helped us conduct this research. This study was approved by the research deputy of Bushehr University of Medical Sciences.

\section{Footnotes}

Authors' Contribution: Azita Noroozi contributed to the critical revision of the manuscript, as well as the final approval of the study. Rahim Tahmasebi contributed to the study design, data analysis, and auditing and drafting of the article. Also, Maliheh Saeed Firoozabadi contributed to the provision and collection of the data.

\section{Funding/Support: None.}

Declaration of Interest: The authors declare no conflicts of interest.

\section{References}

1. Li Z, Yao Y, Han W, Yu Y, Liu Y, Tao Y, et al. Smoking Prevalence and Associated Factors as well as Attitudes and Perceptions towards Tobacco Control in Northeast China. Int J Environ Res Public Health. 2015;12(7):8606-18. doi: 10.3390/ijerph120708606. [PubMed: 26206569].

2. An FR, Xiang YT, Yu L, Ding YM, Ungvari GS, Chan SW, et al. Prevalence of nurses' smoking habits in psychiatric and general hospitals in China. Arch Psychiatr Nurs. 2014;28(2):119-22. doi: 10.1016/j.apnu.2013.11.008. [PubMed: 24673786].

3. Halimi L, Haghdoost AA, Mohammad Alizadeh S. Prevalence of cigarette smoking among Iranian women: a systematic review and meta-analysis. Med J Islam Repub Iran. 2013;27(3):132-40. [PubMed: 24791123].

4. Benowitz NL, Hatsukami D. Gender differences in the pharmacology of nicotine addiction. Addict Biol. 1998;3(4):383-404. doi: 10.1080/13556219871930. [PubMed: 26735114].
5. Maziak W, Ward KD, Afifi Soweid RA, Eissenberg T. Tobacco smoking using a waterpipe: a re-emerging strain in a global epidemic. Tob Control. 2004;13(4):327-33. doi: 10.1136/tc.2004.008169. [PubMed: 15564614].

6. Aghamolaei T, Tavafian SS, Zare S. Health related quality of life in elderly people living in Bandar Abbas, Iran: a population-based study. Acta Medica Iranica. 2010;48(3):185.

7. Smith-Simone SY, Curbow BA, Stillman FA. Differing psychosocial risk profiles of college freshmen waterpipe, cigar, and cigarette smokers. Addict Behav. 2008;33(12):1619-24. doi: 10.1016/j.addbeh.2008.07.017. [PubMed: 18783890$]$.

8. Jackson D, Aveyard P. Waterpipe smoking in students: prevalence, risk factors, symptoms of addiction, and smoke intake. Evidence from one British university. BMCPublic Health. 2008;8:174. doi: 10.1186/1471-24588-174. [PubMed: 18498653].

9. Watad W, Sukhera J, Shushan S, Kazlak M, Skinner HA, Alnueirat AA, et al. Water Pipe Smoking: Effects, Attitudes and Directions.J Smoking Cessation. 2012;4(01):18-25. doi:10.1375/jsc.4.1.18.

10. Cobb C, Ward KD, Maziak W, Shihadeh AL, Eissenberg T. Waterpipe tobacco smoking: an emerging health crisis in the United States. Am J Health Behav. 2010;34(3):275-85. [PubMed: 20001185].

11. Akl EA, Gaddam S, Gunukula SK, Honeine R, Jaoude PA, Irani J. The effects of waterpipe tobacco smoking on health outcomes: a systematic review. Int J Epidemiol. 2010;39(3):834-57. doi: 10.1093/ije/dyq002. [PubMed: 20207606].

12. Raad D, Gaddam S, Schunemann HJ, Irani J, Abou Jaoude P, Honeine $\mathrm{R}$, et al. Effects of water-pipe smoking on lung function: a systematic review and meta-analysis. Chest. 2011;139(4):764-74. doi: 10.1378/chest.10-0991. [PubMed: 20671057].

13. Ajzen I. The theory of planned behavior. Organiz Behav Human Decision Process. 1991;50(2):179-211. doi:10.1016/0749-5978(91)90020-t.

14. Ajzen I. In: Handbook of theories of social psychology. Lange PAM, Kruglanski AW, Higgins ET, editors. London UK: Sage; 2012. pp. 43859.The theory of planned behavior.

15. Glanz K, Rimer BK, Viswanath K. Health behavior and health education: theory, research, and practice. John Wiley \& Sons; 2008.

16. Hyland A, Borland R, Li Q, Yong HH, McNeill A, Fong GT, et al. Individual-level predictors of cessation behaviours among participants in the International Tobacco Control (ITC) Four Country Survey. Tob Control. 2006;15 Suppl 3:iii83-94. doi: 10.1136/tc.2005.013516. [PubMed: 16754952].

17. Perkins MB, Jensen PS, Jaccard J, Gollwitzer P, Oettingen G, Pappadopulos E, et al. Applying theory-driven approaches to understanding and modifying clinicians' behavior: what do we know? Psychiatr Serv. 2007;58(3):342-8. doi: 10.1176/ps.2007.58.3.342. [PubMed: 17325107].

18. Puffer S, Rashidian A. Practice nurses' intentions to use clinical guidelines. J Adv Nurs. 2004;47(5):500-9. doi: 10.1111/j.13652648.2004.03129.x. [PubMed: 15312113].

19. Su X, Li L, Griffiths SM, Gao Y, Lau JT, Mo PK. Smoking behaviors and intentions among adolescents in rural China: the application of the Theory of Planned Behavior and the role of social influence. Addict Behav. 2015;48:44-51. doi: 10.1016/j.addbeh.2015.04.005. [PubMed: 25973776].

20. Samdal O, Wold B, Klepf KI, Kannas L. Students' Perception of School and Their Smoking and Alcohol Use: A Cross-National Study. Addict Res. 2009;8(2):141-67. doi: 10.3109/16066350009004417.

21. World Health Organization . WHO report on the global tobacco epidemic: the MPOWER package. Geneva: World Health Organization; 2008.

22. Hyland A, Li Q, Bauer JE, Giovino GA, Steger C, Cummings KM. Predictors of cessation in a cohort of current and former smokers followed over 13 years. Nicotine Tob Res. 2004;6 Suppl 3:S363-9. [PubMed: 15799599]. 
23. Siahpush M, Borland R, Scollo M. Factors associated with smoking cessation in a national sample of Australians. Nicotine Tob Res. 2003;5(4):597-602. doi: 10.1080/1462220031000118711. [PubMed: 12959798].

24. Lando H, Hennrikus D, McCarty M, Vessey J. Predictors of quitting in hospitalized smokers. Nicotine Tob Res. 2003;5(2):215-22. doi: 10.1080/0955300031000083436. [PubMed:12745494].

25. Broms U, Silventoinen K, Lahelma E, Koskenvuo M, Kaprio J. Smoking cessation by socioeconomic status and marital status: the contribution of smoking behavior and family background. Nicotine Tob Res. 2004;6(3):447-55. doi:10.1080/14622200410001696637. [PubMed: 15203778].

26. Kline RB. Principles and Practice of Structural Equation Modeling, (Methodology In The Social Sciences). New York: Guilford Press; 2011.

27. Lawshe CH. A Quantitative Approach to Content Validity. Personnel Psychol. 1975;28(4):563-75. doi: 10.1111/j.1744-6570.1975.tb01393.x.

28. Shiffman S, Waters A, Hickcox M. The nicotine dependence syndrome scale: a multidimensional measure of nicotine dependence. Nicotine Tob Res. 2004;6(2):327-48. doi: 10.1080/1462220042000202481. [PubMed: 15203807].

29. Schumacker RE, Lomax RG. A beginner's guide to structural equation modeling. Psychology Press; 2004.

30. Hyde J, Hankins M, Deale A, Marteau TM. Interventions to increase self-efficacy in the context of addiction behaviours: a systematic literature review. J Health Psychol. 2008;13(5):607-23. doi: 10.1177/1359105308090933. [PubMed: 18519435].

31. Shi Y, Ehlers S, Warner DO. The theory of planned behavior as applied to preoperative smoking abstinence. PLoS One. 2014;9(7):e103064. doi: 10.1371/journal.pone.0103064. [PubMed: 25057969].

32. Gwaltney CJ, Metrik J, Kahler CW, Shiffman S. Self-efficacy and smoking cessation: a meta-analysis. Psychol Addict Behav. 2009;23(1):56-66. doi: 10.1037/a0013529. [PubMed: 19290690].

33. Topa G, Moriano JA. Theory of planned behavior and smoking: meta-analysis and SEM model. Subst Abuse Rehabil. 2010;1:23-33. doi: 10.2147/SAR.S15168. [PubMed: 24474850].

34. Webb TL, Sheeran P. Does changing behavioral intentions engen- der behavior change? A meta-analysis of the experimental evidence. Psychol Bull. 2006;132(2):249-68. doi: 10.1037/0033-2909.132.2.249. [PubMed: 16536643].

35. Al-Naggar RA, Bobryshev YV, Anil S. Pattern of shisha and cigarette smoking in the general population in Malaysia. Asian Pac J Cancer Prev 2014;15(24):10841-6. [PubMed: 25605187].

36. Mohammadpoorasl A, Abbasi Ghahramanloo A, Allahverdipour $\mathrm{H}$ Modaresi Esfeh J. Prevalence of Hookah smoking in relation to religiosity and familial support in college students of Tabriz, northwest of Iran. J Res Health Sci. 2014;14(4):268-71. [PubMed: 25503281].

37. Lynam I, Catley D, Harris KJ, Goggin K, Berkley-Patton J, Thomas J. African American smokers' intention to use pharmacotherapy for cessation. Am J Health Behav. 2012;36(5):615-27. doi: 10.5993/AJHB.36.5.4 [PubMed: 22584089].

38. Poulsen LH, Osler M, Roberts C, Due P, Damsgaard MT, Holstein BE. Exposure to teachers smoking and adolescent smoking behaviour: analysis of cross sectional data from Denmark. Tob Control. 2002;11(3):246-51. [PubMed: 12198278].

39. Panday S, Reddy SP, Ruiter RA, Bergstrom E, de Vries H. Determinants of smoking among adolescents in the Southern CapeKaroo region, South Africa. Health Promot Int. 2007;22(3):207-17. doi: 10.1093/heapro/dam018. [PubMed: 17584782].

40. Guo Q, Johnson CA, Unger JB, Lee L, Xie B, Chou CP, et al. Utility of the theory of reasoned action and theory of planned behavior for predicting Chinese adolescent smoking. Addict Behav. 2007;32(5):106681. doi: 10.1016/j.addbeh.2006.07.015. [PubMed: 16934414].

41. Hu SC, Lanese RR. The applicability of the theory of planned behavior to the intention to quit smoking across workplaces in southern Taiwan. Addict Behav. 1998;23(2):225-37. [PubMed: 9573426].

42. Armitage CJ, Conner M. Efficacy of the Theory of Planned Behaviour: a meta-analytic review. Br J Soc Psychol. 2001;40(Pt 4):471-99. [PubMed: 11795063].

43. Dolcini MM, Adler NE, Lee P, Bauman KE. An assessment of the validity of adolescent self-reported smoking using three biological indicators. Nicotine Tob Res. 2003;5(4):473-83. [PubMed: 12959785]. 